\title{
RELAKSASI PERNAFASAN DENGAN TEKNIK BALLON BLOWING TERHADAP PENINGKATAN SATURASI OKSIGEN PADA PASIEN PPOK
}

\author{
Ni Made Dwi Yunica Astriani ${ }^{1}$, Putu Indah Sintya Dewi ${ }^{2}$, Kadek Hendri Yanti ${ }^{3}$ \\ Sekolah Tinggi Ilmu Kesehatan Buleleng ${ }^{1,2,3}$ \\ astrianiyunica1@gmail.com ${ }^{1}$
}

\begin{abstract}
ABSTRAK
Tujuan dari penelitian ini adalah untuk mengetahui pengaruh relaksasi pernafasan dengan teknik ballon blowing terhadap peningkatan saturasi oksigen pada pasien PPOK. Desain penelitian menggunakan rancangan one group pre-post test design. Hasil penelitian pada 30 responden PPOK menunjukkan prevalensi jenis kelamin sebagian besar responden berjenis kelamin laki-laki 73,3 \% dengan usia rata-rata 61,87 dengan rentang umur 45- 80 tahun, rata-rata (mean) pre-test adalah 89,27 dan rata-rata (mean) post-test adalah 94,53 dengan p-value 0,000. Simpulan, terdapat pengaruh relaksasi pernafasan dengan teknik ballon blowing terhadap peningkatan saturasi oksigen pada pasien PPOK di RSUD Kabupaten Buleleng.
\end{abstract}

Kata Kunci : Peningkatan Saturasi Oksigen, PPOK, Teknik Ballon Blowing

\section{ABSTRACT}

The purpose of this study was to determine the effect of respiratory relaxation with the ballon blowing technique on increasing oxygen saturation in COPD patients. The study design used a one group pre-post test design. The results of the 30 COPD respondents showed the gender prevalence of the majority of male respondents $73.3 \%$ with an average age of 61.87 with an age range of 45-80 years, the mean (pre-test) was 89, 27 and the post-test mean is 94.53 with a p-value of 0,000. Conclusions, there Is An Influence of breathing relaxation with ballon blowing technique on increasing oxygen saturation in COPD patients in RSUD Buleleng Regency.

Keywords: Increased Oxygen Saturation, COPD, Ballon Blowing Technique

\section{PENDAHULUAN}

Penelitian yang pernah dilakukan Juniadin et al, (2019) dengan responden pasien dewasa, rata-rata umur ditas 65 tahun menggunakan rancangan pre dan pos test desain yang menyatakan latihan pernafasan pursed lip breathing berguna untuk memperbaiki ventilasi, meningkatkan kerja otot abdoman dan toraks. Penelitian ini juga menyatakan terdapat peningkatan saturasi oksigen setelah diberikan intervensi meniup balon dan lip breathing.

Penelitian yang dilakukan oleh Suryadinata (2018) mengatakan peningkatan jumlah radikal bebas dapat berpengaruh pada inflamasi tubuh. Peningkatan tersebut dapat memicu inflamasi pada saluran pernafasan. Paparan asap rokok menimbulkan ketidakseimbangan jumlah radikal bebas yang dihasilkan dalam tubuh. Merokok 
merupakan salah satu penyebab terjadinya PPOK. Perokok berat merupakan penyebab kematian akibat PPOK terkait dengan banyaknya rokok yang dihisap, umur pertama merokok dan status terakhir merokok. Selain itu penyebab PPOK yaitu polusi udara semakin kotor udara, semakin banyak pula kotoran yang masuk kedalam saluran pernapasan manusia. Polutan udara ini dapat berupa asap, debu, gas, maupun uap. Semakin seseorang terpapar polutan maka semakin mudah dan semakin cepat seseorang mengalami penyakit saluran pernapasan kronik.

Prevalensi merokok pada populasi usia 10-18 tahun meningkat dari 7,2 \% pada tahun 2013 dan 9,1\% pada tahun 2018. Di Bali prevalensi merokok meningkat dari 20 \% pada tahun 2013 dan 23,5 \% tahun 2018 (Riskesdas, 2018).

Penelitian yang dilakukan oleh Kusumawardani et al, (2017) menunjukkan bahwa riwayat penyakit PPOK pada penduduk berumur 30 tahun keatas ditemukan sebesar $3,7 \%$. Prevalensi cendrung laki-laki lebih tinggi (4,2\% dibandingkan dengan perempuan $3,3 \%$ ). Sedangkan pada umur, prevalensi PPOK meningkat pada kelompok lanjut usia yaitu sebesar 7,9\%.

Latihan pernafasan dapat dilakukan dalam beberapa posisi karena distribusi udara dan sirkulasi pulmonal beragam sesuai dengan posisi dada. Hal ini sejalan dengan hasil jurnal Mertha et al, (2018) didapatkan hasil bahwa nilai saturasi oksigen sebelum dilakukan intervensi rata-rata sebesar $89,80 \%$ dan setelah dilakukan intervensi rata-rata sebesar $92.20 \%$ dengan selisih rat-rata sebesar 0,5\%. Hal ini menunjukkan bahwa intervensi deep breathing exercise dapat meningkatkan saturasi oksigen pada pasien PPOK.

Penelitian yang dilakukan oleh Harun, Anantasari (2019) yang dibagi menjadi dua kelompok yanitu kelompok perlakuan diberikan pernafasan difragma sedangkan kelompok kontrol diberikan terapi farmakologis. Hasil penelitian menunjukkan peningkatatan pada kelompok perlakuan 0,74 \% dibandingkan kelompok control. Pernafasan difragma meningkatkan peran difragma melakukan respirasi untuk tekanan inspirasi sehingga udara lebih banyak masuk ke paru-paru.

Adapun penelitian yang mendukung asumsi diatas yaitu menurut Tarigan, Juliandi (2018) dengan hasil terdapat peningkatan saturasi oksigen setelah diberika intervensi. Dengan rata-rata saturasi oksigen sebelum diberikan intervensi yaitu 96,72\%. rata-rata saturasi oksigen setelah diberikan intervensi yaitu $98,11 \%$, ada pengaruh latihan nafas pursed lip breathing terhadap peningkatan saturasi oksigen penderita PPOK dengan nilai $\mathrm{p}=0,00$.

Penelitian yang dilakukan oleh Wahidati et al, (2019) suatu penelitian quasi eksperimental dengan jumlah sampel 34 responden didapatkan hasil pursed lips breathing lebih efektif dengan rata-rata 1,23 dibandingkan dengan tripod position 0,29. Latiahan nafas dapat membantu meningkatkan masuknya oksigen ke alveoli sehingga meningkatkan saturasi oksigen.

Saturasi oksigen pasien PPOK dapat ditingkatkan dengan terapi nonfarmakologi yaitu relaksasi pernafasan yaitu nafas dalam diindikasikan pada pasien PPOK dan dispnea. Latihan relaksasi pernafasan dapat meningkatkan inflasi alveolar maksimal, meningkatkan relaksasi otot, meningkatkan ventilasi alveoli, memelihara pertukaran gas, menghilangkan ansietas, dan mengurangi kerja pernafasan. Latihan pernafasan dapat dilakukan dalam beberapa posisi karena distribusi udara dan sirkulasi pulmonal beragam sesuai dengan posisi dada. Hal ini sejalan dengan hasil jurnal Mertha et al, (2018) menunjukkan bahwa nilai saturasi oksigen sebelum dilakukan intervensi ratarata sebesar $89,80 \%$ dan setelah dilakukan intervensi rata-rata sebesar $92.20 \%$ dengan 
selisih rat-rata sebesar $0,5 \%$. Hal ini menunjukkan bahwa intervensi deep breathing exercise dapat meningkatkan saturasi oksigen pada pasien PPOK.

Penelitian yang dilakukan oleh Zul, Suza (2019) dengan jumlah sampel penelitian 70 responden yang terbagi menjadi 2 kelompok dengan tehnik quasi eksperimen didapatkan hasil latihan nafas buteyko dan ballons blowing sama-sama dapat meningkatkan nilai arus puncak ekspirasi.

Relaksasi pernapasan mempunyai banyak teknik salah satunya adalah dengan menggunakan balon (ballon blowing) teknik relaksasi dengan meniup balon dapat membantu otot intracosta mengelevasikan otot diafragma dan kosta. Sehingga memungkinkan untuk menyerap oksigen, mengubah bahan yang masih ada dalam paru dan mengeluarkan karbondioksida dalam paru. Meniup balon sangat efektif untuk membantu ekspansi paru sehingga mampu mensuplai oksigen dan mengeluarkan karbondioksida yang terjebak dalam paru pada pasien dengan gangguan fungsi pernapasan. Peningkatan ventilasi alveoli dapat meningkatkan suplai oksigen, sehingga dapat dijadikan sebagai terapi dalam peningkatan saturasi oksigen. Dalam hal ini perawat menganjurkan kepada klien relaksasi pernafasan yaitu nafas dalam dengan teknik meniup balon (Tunik et al, 2017).

Hal ini sejalan dengan hasil penelitian Royani (2017) hasil penelitian ini menunjukkan bahwa terapi aktivitas meniup balon dilakukan selama 1 bulan, dimana perlakuan dilakukan seminggu 3 kali. Setelah dilakukan intervensi meniup balon didapatkan frekuensi yang fungsi parunya baik sebanyak $18(60 \%)$ dan fungsi parunya kurang baik sebanyak 12 responden (40\%).

Berdasarkan studi pendahuluan yang dilakukan di RSUD Kabupaten Buleleng, didapatkan jumlah penderita PPOK dalam tiga bulan terakhir yaitu pada bulan November, Desember 2018 dan Januari 2019 yaitu sebanyak 38 orang. Berdasarkan hasil observasi dengan 8 orang pasien RSUD Kabupaten Buleleng di dapatkan rata-rata hasil frekuensi pernafasan yaitu \pm 25 /menit. Dari hasil pemeriksaan saturasi oksigen didapatkan 6 orang pasien dengan saturasi oksigen dibawah normal dan, 2 orang pasien memiliki saturasi oksigen dengan rata-rata normal. Selain perawat memberikan teknik relaksasi pernafasan yaitu teknik nafas dalam pasien juga diberikan asuhan keperawatan yaitu terapi oksigen dan posisi semi fowler.

Penelitian tentang PPOK yang telah dilakukan sebelumnya hanya dengan metode terapi oksigen, dan relaksasi nafas dalam. Namun, pada penelitian ini lebih menekankan pada penggunaan teknik relaksasi ballon blowing. Intervensi ini masih terbatas sehingga belum dilakukan dengan optimal. Relaksasi yang dilakukan ini berfokus pada kemampuan pasien dalam menggunakan teknik ballon blowing.

\section{METODE PENELITIAN}

Penelitian ini merupakan penelitian eksperimen dimana subyek penelitiannya adalah pasien PPOK di RSUD Kabupaten Buleleng, karena dalam penelitian memberikan perlakuan atau intervensi pada objek yang akan diteliti. Desain yang digunakan dalam penelitian ini yaitu one group pre-test dan post-test. Melakukan pre test untuk mengetahui nilai saturasi oksigen pada pasien PPOK sebelum diberikan teknik relaksasi pernafasan dengan teknik ballon blowing. Setelah itu memberikan teknik relaksasi pernafasan dengan teknik ballon blowing pada pasien PPOK selama 510 menit selama 4 minggu. Dilakukan post test untuk melihat perubahan saturasi oksigen. 
Teknik sampling yang digunakan adalah non-probability sampling (total sampling) dengan jumlah sampel 30 orang responden. Kaji etik dalam penelitian ini dilakukan oleh Komite Etik Penelitian Kesehatan (KEPK) Sekolah Tinggi Ilmu Kesehatan Buleleng.

\section{HASIL PENELITIAN}

Tabel. 1

Distribusi Frekuensi Usia

\begin{tabular}{clllll}
\hline & N & Mean & Min & Max & Sd \\
\hline Usia & 30 & 61,87 & 45 & 80 & 9.558 \\
\hline Sumber: Data Primer (2019) & & & &
\end{tabular}

Berdasarkan tabel 1 didapatkan hasil bahwa rata-rata umur responden yaitu 61,87 dengan rentang umur 45- 80 tahun.

Tabel. 2

Distribusi Frekuensi Jenis Kelamin

\begin{tabular}{ccc}
\hline Usia & Frekuensi (f) & Persentase (\%) \\
\hline Laki-laki & 22 & 73,3 \\
Perempuan & 8 & 26,7 \\
\hline Total & 30 & 100 \\
\hline
\end{tabular}

Sumber: Data Primer (2019)

Berdasarkan tabel 2 didapatkan dari 30 responden, distribusi frekuensi responden sebagian besar responden berjenis kelamin laki-laki dan sebagian kecil perempuan.

Tabel. 3

Saturasi Oksigen Responden Sebelum Diberikan

Teknik Ballon Blowing

\begin{tabular}{ccccccc}
\hline & N & Mean & Min & Max & SD & $95 \%$ CI \\
\hline Pre Test & 30 & 89,27 & 86 & 93 & 1,999 & $88,52-90,01$ \\
\hline
\end{tabular}

Sumber: Data Primer (2019)

Berdasarkan tabel 3 menunjukkan bahwa rata-rata nilai saturasi oksigen pasien PPOK sebelum diberikan intervensi adalah 89,27 dengan standar deviasi 1,999. Nilai saturasi oksigen terendah 86 dan tertinggi 93.

Tabel. 4

Saturasi Oksigen Responden Sebelum Diberikan Teknik Ballon Blowing

\begin{tabular}{ccccccc}
\hline & N & Mean & Min & Max & SD & $95 \%$ CI \\
\hline Post test & 30 & 94,53 & 91 & 99 & 2,417 & $93,63-95,44$ \\
\hline \multicolumn{2}{l}{ Sumber: Data Primer (2019) }
\end{tabular}


Berdasarkan tabel 4 menunjukkan rata-rata nilai saturasi oksigen sesudah diberikan intervensi dari 30 responden adalah 94,53 dengan standar deviation 2,417 nilai saturasi oksigen terendah 91 dan tertinggi 99 . Data ini menunjukkan nilai saturasi oksigen pasien PPOK setelah diberikan intervensi sebagian besar mengalami peningkatan nilai saturasi oksigen menjadi $\mathrm{SaO} 2$ normal.

Tabel. 5

Hasil Analisis Pre dan Post Test

\begin{tabular}{|c|c|c|c|}
\hline & & Mean & P. Value \\
\hline \multirow[t]{2}{*}{ Pair 1} & Pretest & 89.27 & 0,000 \\
\hline & Posttest & 94.53 & 0,000 \\
\hline
\end{tabular}

Sumber: Data Primer (2019)

Berdasarkan tabel 5 dapat dilihat bahwa ada pengaruh pada intervensi relaksasi pernafasan dengan teknik ballon blowing terhadap saturasi oksigen pasien PPOK. Hasil perhitungan yang didapat dengan program komputer menunjukkan p-value 0,000 maka dapat disimpulkan nilai $\mathrm{p}$ lebih kecil dari $0,05(\mathrm{p}<0,05)$ yang berarti terdapat pengaruh relaksasi penafasan dengan teknik ballon blowing terhadap saturasi oksigen pasien PPOK di ruang poli paru RSUD Kabupaten Buleleng.

\section{PEMBAHASAN}

\section{Karakteristik Responden}

Hasil penelitian ini menunjukan bahwa dari 30 subjek penelitian, mayoritas pasien PPOK berdasarkan usia didapatkan seluruhnya berada pada usia diatas 40 tahun. Hasil penelitian ini sejalan dengan hasil penelitian yang menyatakan bahwa mayoritas pasien PPOK yaitu diatas 40 tahun (Yuningsih, Islamic, 2017). Penelitian lain juga menyatakan hal yang sama bahwa seluruh pasien PPOK berada pada usia diatas 40 tahun (Agustina et al, 2017). Semakin bertambahnya usia semakin besar risiko menderita PPOK. pada pasien yang didiagnosa PPOK sebelum usia 40 tahun, besar kemungkinan mengalami gangguan genetik berupa defisiensi $\alpha$ I antitrypsin. PPOK dapat berpengaruh terhadap penurunan fungsi paru dan perubahan fisiologis yang berkaitan dengan penuaan dan mengakibatkan penyumbatan jalan napas sehingga mempengaruhi suplai oksigen, elastisitas paru dan gangguan ventilasi paru.

Sejalan dengan penelitian Tarigan, Juliandi (2018) yang menunjukkan bahwa mayoritas responden dalam penelitian ini berusia antara 60 sampai 70 tahun. Hal ini terjadi dimana semakin bertambah usia maka semakin resiko untuk mengalami gangguan pernapasan, dimana pada lanjut usia juga terjadi perubahan pada bentuk thorak dan pola napas.

Dilihat dari karakteristik jenis kelamin responden yang mengalami PPOK pada penelitian ini sebagian besar adalah laki-laki yaitu sebanyak 22 dan perempuan 8 . Pada umumnya PPOK dapat terjadi pada laki-laki dan perempuan tetapi laki-laki lebih beresiko dan insidennya lebih banyak. Sejalan dengan penelitian yang dilakukan oleh Alamsyah (2019) penelitian pada 30 responden dengan hasil prevalensi laki-laki 63,3\% sedangkan perempuan 36,7 \%. Hal ini mengingat bahwa laki-laki lebih dominan memiliki kebiasa merokok dimana merokok merupakan penyebab utama terjadinya PPOK, dengan risiko 30 kali lebih besar pada perokok dibandingkan dengan bukan perokok. Dan menjadi penyebab dari $85-90 \%$ kasus PPOK. Kurang lebih 15-20\% 
perokok akan mengalami PPOK. Hal ini akan mengakibatkan hipersekresi yang dihasilkan oleh sel goblet, dimana sel goblet memproduksi sekret yang cukup banyak yang dapat masuk ke saluran pernapasan. Penelitian yang dilakukan oleh Monalisa, Budi (2018) penelitian yang dilakukan pada 80 responden petugas kebersihan di kota Purwekerto perilaku merokok sebesar 72,5\% dan tidak merokok sebesar 27,5\%.

Hasil penelitian Tarigan, Juliandi (2018) juga menjelaskan bahwa 36 orang responden sebagian besar penderita PPOK di RSUP. H. Adam Malik Medan berjenis kelamin laki-laki sebanyak 80,6 \% sedangkan jenis kelamin wanita hanya sebesar 19,4 $\%$. Hal ini disebabkan karena faktor gaya hidup yang berbeda, dimana laki-laki lebih banyak merokok dan bekerja di lingkungan terbuka dibandingkan dengan wanita, Merokok dan pekerjaan tertentu pada tempat yang berdebu dapat menjadi predisposisi penyakit paru.

\section{Saturasi Oksigen Sebelum Diberikan Teknik Ballon Blowing}

Sebelum diberikan intervensi relaksasi pernafasan dengan teknik ballon blowing pada pasien PPOK di ruang poli paru RSUD Kabupaten Buleleng, terlebih dahulu peneliti melakukan pendekatan komunikasi untuk membina hubungan saling percaya antara pasien dengan peneliti, setelah itu melakukan penelitian. Dari 30 responden nilai saturasi oksigen pasien PPOK di ruang poli paru sebelum diberikan intervensi didapatkan bahwa frekuensi saturasi oksigen terendah adalah $86 \%$ dan saturasi oksigen tertinggi 93\%. Pada umumnya pada pasien PPOK akan mengalami gangguan produksi sekret dimana sesorang memproduksi sekret berlebih sehingga menyebabkan penderita mengalami penurunan gas darah saturasi oksigen. Dari hasil diatas nilai saturasi oksigen pasien PPOK sebelum diberikan intervensi terdapat nilai saturasi oksigen terendah yang dapat diartikan bahwa pasien tersebut memiliki kadar oksigen dibawah normal. Tunik et al, (2017) mengatakan selain pemberian nafas dalam, teknik relaksasi nafas dengan teknik ballon blowing sangat penting dilakukan dimana teknik ini mampu meningkatkan ventilasi alveoli, memelihara pertukaran gas dengan baik dan mampu mengeluarkan udara yang terjebak dalam alveoli sehingga dapat meningkatkan saturasi oksigen.

Penelitian oleh Balraj, Rudolf (2018) penelitian pada 80 pasien yang terdiagnosa menderita PPOK rawat jalan di RSUD Deli Serdang Lubuk Pakam dengan hasil keluhan utama berupa sesak nafas sebesar 52,5\% sedangkan keluhan utama berupa batuk dahak dan sesak nafas sebesar 47,5\%.

Adapun penelitian yang mendukung asumsi diatas yaitu menurut Tarigan, Juliandi (2018) dengan hasil terdapat peningkatan saturasi oksigen setelah diberikan intervensi. Dengan rata-rata saturasi oksigen sebelum diberikan intervensi yaitu $96,72 \%$. rata-rata saturasi oksigen setelah diberikan intervensi yaitu $98,11 \%$, ada pengaruh latihan nafas pursed lip breathing terhadap peningkatan saturasi oksigen penderita PPOK dengan nilai $\mathrm{p}=0,00$.

\section{Saturasi Oksigen Setelah Diberikan Teknik Ballon Blowing}

Penelitian ini menunjukan bahwa setelah diberikan teknik relaksasi nafas dengan teknik ballon blowing, didapatkan bahwa nilai saturasi oksigen tertinggi adalah $99 \%$ dan terendah adalah 91\% dengan rata-rata saturasi oksigen sebesar 94,53 Hal ini menunjukan bahwa pemberian relaksasi nafas dengan teknik ballon blowing dapat meningkatkan saturasi oksigen pada pasien PPOK.

Penelitian yang dilakukan oleh Lilyana (2017); Padila et al, (2019) terkait manajemen nonfarmakoterapi bagi pasien PPOK metode yang digunakan adalah 
tinjauan pustaka dan hasil penelitianny menyatakan bahwa terapi nonfarmakologi yang diberikan pada pasien PPOK antara lain: berhenti merokok, latihan dan rehabilitasi paru berupa latihan fisik serta latihan napas khusus serta bantuan psikis, dan asupan nutrisi yang adekuat.

Penelitian ini didukung oleh penelitian serupa yang pernah dilakukan Juniadin et al, (2019) dengan responden pasien dewasa, rata-rata umur ditas 65 tahun menggunakan rancangan pre dan pos test desain yang menyatakan latihan pernafasan pursed lip breathing berguna untuk memperbaiki ventilas, meningkatkan kerja otot abdoman dan toraks. Penelitian ini juga memyatakan terdapat peningkatan saturasi oksigen setelah diberikan intervensi meniup balon dan lip breathing.

Sejalan dengan penelitian yang dilakukan oleh Yuningsih, Islamic (2017) juga dapat mendukung penelitian ini. Hasil penelitian menyatakan bahwa tujuan dari latihan pernafasan dan nafas dalam adalah untuk mencapai ventilasi yang lebih terkontrol serta mengurangi kerja pernafasan, mengurangi udara yang terperangkap. Latihan pernafasan dirancang dan dijalankan untuk mencapai ventilasi. Hal ini dibuktikan dalam pemberian intervensi dengan melatih otot pernafasan serta latihan nafas dalam secara teratur terbukti efektif meningkatkan ekspansi dada dan paru yang berdampak pada saturasi oksigen pasien.

\section{Pengaruh Relaksasi Pernafasan dengan Teknik Ballon Blowing terhadap Peningkatan Saturasi Oksigen pada Pasien PPOK}

Dari hasil penelitian ini didapatkan bahwa terdapat perbedaan hasil saturasi oksigen antara sebelum dan sesudah pemberian relaksasi pernafasan dengan teknik ballon blowing.Sehingga dapat diartikan bahwa relaksasi pernafasan dengan teknik ballon blowing berpengaruh terhadap peningkatan saturasi oksigen pada pasien PPOK di ruang poli paru RSUD Kabupaten Buleleng.

Hasil uji analisa data dengan menggunakan uji paired dependent t-test menunjukan bahwa terdapat pengaruh relaksasi pernafasan dengan teknik ballon blowing terhadap peningkatan saturasi oksigen pada pasien PPOK di RSUD Kabupaten Buleleng. Hal ini sejalan dengan penelitian yang dilakukan Tunik et al, (2017) penelitian ini dilakukan selama 1 minggu dari 36 responden didapatkan hasil nilai signifikan yang diperoleh $(\mathrm{p}<0,05)$, dengan hasil terdapat perbedaan nilai pengukuran terhadap variabel saturasi oksigen pasien sebelum dan sesudah diberikan intervensi berupa breathing relaxtation dengan teknik ballon blowing pada pasien PPOK.

Berdasarkan penelitian Sukartini, Sriyono (2017) menunjukkan bahwa ada pengaruh antara frekuensi nafas dengan latihan nafas modifikasi meniup balon dengan hasil uji paired t-test $\mathrm{p}=0,001$ kelompok perlakuan dan kelompok kontrol dan antara kelompok perlakuan dan kelompok kontrol $\mathrm{p}=0,007$. Hasil pemeriksaan vital capacity didapatkan bahwa ada pengaruh antara vital capacity dengan latihan modifikasi meniup balon pada kelompok perlakuan $\mathrm{p}=0,018$ kelompok kontrol $\mathrm{p}=0,020$ dan antara kelompok perlakuan dan kelompok kontrol $\mathrm{p}=0,026$.

Selanjutnya Tarigan, Juliandi (2018) menjelaskan bahwa pasien PPOK yang rutin melakukan latihan nafas bisa berefek positip terhadap perkembangan paru-parunya. Breathing exercise didesain untuk memperbaiki fungsi otot-otot respirasi, meningkatkan ventilasi dan oksigenisasi. Exercise aktive ROM pada shoulder dan trunk akan membantu ekspansi thorax, memfasilitasi deep breathing dan juga bermanfaat untuk menstimulasi reflex batuk. Penelitian ini juga menunjukkan bahwa sebelum dilakukan latihan nafas dalam pursed lip breathing rerata saturasi oksigen responden adalah 96,72 
$\%$, setelah dilakukan pursed lip breathing saturasi oksigen naik sebesar 1,39 menjadi $98,11 \%$. Hal ini menunjukkan bahwa ada pengaruh latihan nafas dalam pursed lip breathing terhadap peningkatan saturasi oksigen penderita PPOK dengan nilai $\mathrm{P}=0,001$

Hasil penelitian menurut Tunik et al, (2017) latihan pernafasan yang dilakukan untuk mencapai ventilasi yang lebih terkontrol dan efisien. Latihan ulang pernafasan dapat meningkatkan inflasi alveolar secara maksimal, meningkatkan relaksasi otot, dan mengurangi kerja nafas. Latihan nafas dengan modifikisasi meniup balon dapat meningkatkan otot pada intracosta dan meningkatkan elevasi diafragma dan kosta, sehingga mampu meningkatkan suplai oksigen dan peningkatkan saturasi oksigen.

Pasien PPOK sangat dianjurkan untuk melakukan teknik latihan pernapasan meliputi pernapasan diafragma dan pursed lips breathing dengan tujuan untuk memperbaiki ventilasi dan mensinkronkan kerja otot abdomen dan toraks. Latihan pernapasan umumnya dilakukan 20-30 menit perhari (sekaligus atau 2x sehari). Pernapasan pursed lips breathing dilakukan dengan cara penderita duduk dan bernafas dengan cara menghembuskan nafas melalui mulut yang hampir tertutup (seperti bersiul) selama 4-6 detik. Cara itu diharapkan dapat menimbulkan tekanan saat ekspirasi sehingga aliran udara melambat dan meningkatkan tekanan dalam rongga perut yang diteruskan sampai bronkioli sehingga kolaps saluran nafas saat ekspirasi dapat dicegah. Pernapasan pursed lips breathing dapat memperbaiki pertukaran gas yang dapat dilihat dengan membaiknya saturasi oksigen arteri. Pursed lips breathing juga memperbaiki pola nafas dan meningkatkan volume tidal. Selain itu, pursed lips breathing bertujuan memberikan manfaat subjektif pada penderita yaitu mengurangi sesak, rasa cemas dan tegang karena sesak (Tarigan \& Juliandi, 2018).

\section{SIMPULAN}

Karakteristik responden berdasarkan jenis kelamin sebagian besar responden berjenis kelamin laki-laki dengan usia terendah 45 tahun sedangkan usia tertinggi 80 tahun. Hasil pengukuran saturasi oksigen pada pasien PPOK setelah diberikan intervensi menunjukan saturasi oksigen meningkat sehingga terdapat pengaruh relaksasi pernafasan dengan teknik ballon blowing terhadap saturasi oksigen pada pasien PPOK.

Ballon blowing sangat efektif untuk membantu ekspansi paru sehingga mampu mensuplai oksigen dan mengeluarkan karbondioksida yang terjebak dalam paru pada pasien dengan gangguan fungsi pernapasan.

\section{SARAN}

\section{Bagi Pelayanan}

Perlu melakukan pendidikan kesehatan tentang PPOK agar masyarakat dapat tahu cara penanggulangan PPOK dan faktor apa saja yang dapat menyebabkan terjadinya PPOK. Kepada masyarakat diharapkan menggunakan teknik relaksasi pernafasan ballon blowing yang telah diketahui manfaatnya untuk meningkatkan saturasi oksigen.

\section{Bagi Keilmuan}

Penelitian ini dapat menambah wawasan dan pengetahuan kepada peserta didik tentang pengaruh relaksasi pernafasan ballon blowing terhadap saturasi oksigen pada pasien PPOK dan dimasukan pada mata kuliah Keperawatan Medikal Bedah sebagai bagian dari topik penatalaksanaan paru pada pasien PPOK. 


\section{Bagi Peneliti Selanjutya}

Penelitian lanjutan dengan menambahkan variabel konfonding untuk melihat faktor - faktor yang mempengaruhi saturasi oksigen pada pasien PPOK dengan menggunakan jumlah sampel yang sesuai.

Penelitian ini dapat memberikan rekomendasi yang bermanfaat bagi pengembangan riset keperawatan serta memberikan petunjuk terhadap penelitian berikutnya untuk meneliti tentang relaksasi pernafasan ballon blowing yang dihubungkan dengan kapasitas vital paru, arus puncak ekspirasi dengan cara memperhatikan faktor-faktor yang mempengaruhi PPOK seperti merokok, alkohol.

\section{DAFTAR PUSTAKA}

Agustina, D. M., Andayani, N., \& Wahyuniati, N. (2017). Hubungan Dukungan Keluarga dengan Kualitas Hidup pada Pasien Penyakit Hubungan Dukungan Keluarga dengan Kualitas Hidup pada Pasien Penyakit Paru Obstruktif Kronik di Poli Paru BLUD RSUD. Zainoel Abidin Banda Aceh

Alamsyah, L. (2019). Hubungan Faktor Resiko dengan Kejadian pada Penyakit Paru Obstruksi Kronik Di Puskesmas Mandala. Jurnal Penelitian Keperawatan Medik, 1(2), 43-47

Balraj Kaur, Rudolf S.Parhusip, P. P. O. S. (2018). Gambaran Diagnostik dan Penatalaksanaan Pasien Penyakit Paru Obstruksi Kronik. Jurnal Kedokteran Methodist, 11(1), 10-13

Harun, A., Ririn, A, M. F. (2019). Prosiding Seminar Nasional Hasil Penelitian dan Pengabdian Masyarakat Seri Ke-2 Tahun 2018 184. Prosiding Seminar Nasional Hasil Penelitian dan Pengabdian Masyarakat Seri Ke-3 Tahun 2019, 53-61

Juniadin, S. Y., \& Irawan, A. M. (2019). Pengaruh Pursed Lip Breathing dan Meniup Balon terhadap Kekuatan Otot Pernafasan,Saturasi Oksigen dan Respiratory Rate Pasien PPOK. Jurnal Ilmiah Keperawatan (Scientific Journal of Nursing). https://doi.org/10.33023/jikep.v5i1.211

Kusumawardani, N., Rahajeng, E., Mubasyiroh, R., \& Suhardi. (2017). Hubungan antara Keterpajanan Asap Rokok dan Riwayat Penyakit Paru Obstruktif Kronik (PPOK) di Indonesia. Jurnal Ekologi Kesehatan. https://doi.org/10.22435/JEK.V15I3.5889.160-166

Lilyana, M. T. A. (2017). Manajemen Nonfarmakologis Terapi bagi Pasien PPOK. Jurnal Ners Lentera, 5(2), 178-182

Mertha, I. M., Putri', P. J. Y., \& Suardana, I. (2018). Pengaruh Pemberian Deep Breathing Exercise terhadap Saturasi Oksigen Pada PPOK. Journal of Nursing, 19

Monalisa, F. A., Utomo, B. S. (2018). Beberapa Faktor Risiko yang Berhubungan dengan Penyakit Paru Obstruktif Kronik (PPOK) Petugas Kebersihan di Kota Purwokerto. Buletin Keslingmas, 37(4), 443-445. https://doi.org/10.31983/keslingmas.v37i4.3796

Padila, P., Febriawati, H., Andri, J., \& Dori, R. A. (2019). Perawatan Infeksi Saluran Pernafasan Akut (ISPA) pada Balita di Wilayah Kerja Puskesmas. Jurnal Kesmas Asclepius, 1(1), 25-34. https://doi.org/10.31539/jka.v1i1.526

Riskesdas. (2018). Hasil Utama Riset Kesehatan Dasar. Kementrian Kesehatan Republik Indonesia, 1-100. https://doi.org/ 
Royani, E. (2017). Pengaruh Terapi Aktivitas Bermain Meniup Balon terhadap Perubahan Fungsi Paru pada Anak dengan Asma di Rumah Sakit Islam Siti Khodijah Palembang. 5

Sukartini, T., \& Sriyono, S. (2017). Latihan Nafas Modifikasi Meniup Balon terhadap Pengembangan Paru pada Pasien Hemathoraks dan Pneumothoraks. 2(1)

Suryadinata, R. V. (2018). Pengaruh Radikal Bebas terhadap Proses Inflamasi pada Penyakit Paru Obstruktif Kronis (PPOK). Amerta Nutrion, 2(4), 317-324. https://doi.org/10.1017/CBO9781107415324.004

Tarigan, A. P. S., \& Juliandi, J. (2018). Pernafasan Pursed Lip Breathing Meningkatkan Saturasi Oksigen Penderita Penyakit Paru Obstruktif Kronis (PPOK) Derajat II. Jurnal Keperawatan Indonesia, 1(2)

Tunik, R. E. M., \& Khoiriyati, A. (2017). Pengaruh Breathing Relaxtation dengan Teknik Ballon Blowing terhadap Saturasi Oksigen dan Perubahan Fisiologs Kecemasan Pasien dengan PPOK

Wahidati, Hi., Dwiningsih, S. U., \& Putrono, P. (2019). The Effectiveness of Tripod Position and Pursed Lips Breathing to Enhance Oxygen Saturation in Patients With COPD. Jendela Nursing Journal, 3(2), 68-76

Yuningsih, Y., \& Islamic, I. (2017). Pengaruh Latihan Nafas Dalam terhadap Peningkatan Saturasi Oksigen pada Klien Terpasang WSD di RSUD Kabupaten Tangerang

Zul, M. I., Dewi, N. F. S. (2019). Perbandingan Latihan Napas Buteyko dan Latihan Blowing Balloons terhadap Perubahan Arus. Persatuan PSerawat Indonesia, 3(2), 93-100 